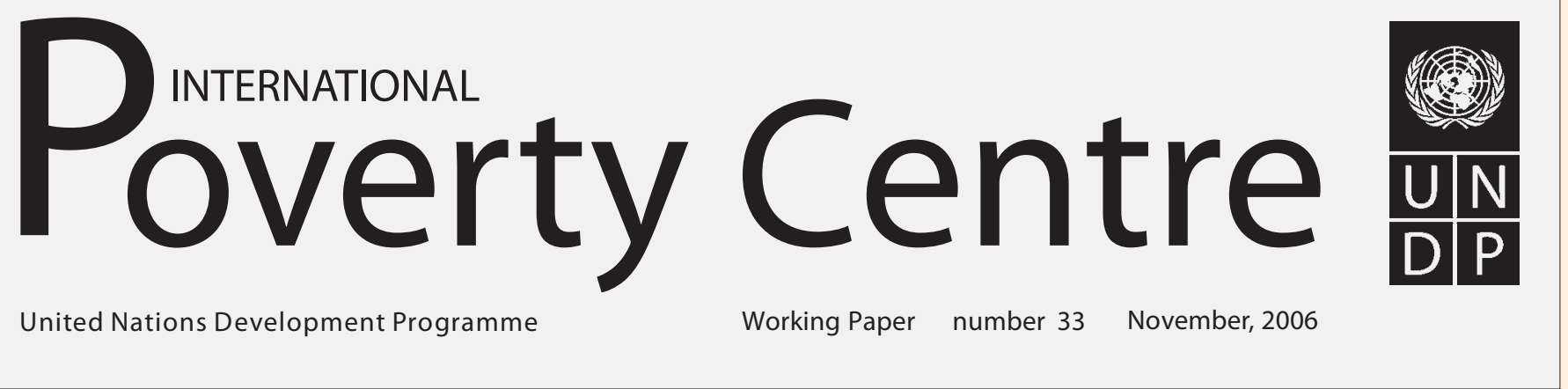

\title{
MEASURING THE IMPACT OF PRICE CHANGES ON POVERTY
}

\author{
Hyun H. Son \\ International Poverty Centre, \\ United Nations Development Programme \\ and \\ Nanak Kalkwani \\ International Poverty Centre, \\ United Nations Development Programme
}




\title{
Copyright $(2006$
}

United Nations Development Programme International Poverty Centre

\author{
International Poverty Centre \\ SBS - Ed. BNDES, $10^{\circ}$ andar \\ 70076900 Brasilia DF \\ Brazil \\ povertycentre@undp-povertycentre.org \\ www.undp.org/povertycentre \\ Telephone +55 6121055000 \\ Fax +556121055001
}

\section{Rights and Permissions}

All rights reserved.

The text and data in this publication may be reproduced as long as the source is cited.

Reproductions for commercial purposes are forbidden.

The International Poverty Centre's Working Papers disseminates the findings of work in progress to encourage the exchange of ideas about development issues. The papers are signed by the authors and should be cited and referred to accordingly. The findings, interpretations, and conclusions expressed in this paper are entirely those of the authors. They do not necessarily represent the views of the International Poverty Centre or the United Nations Development Programme, its Administrator, Directors, or the countries they represent.

Working Papers are available online at http://www.undp.org/povertycentre and subscriptions might be requested by email to povertycentre@undp-povertycentre.org 


\title{
MEASURING THE IMPACT OF PRICE CHANGES ON POVERTY*
}

\author{
Hyun H. Son ${ }^{* *}$ and Nanak Kakwani
}

\begin{abstract}
This paper develops a methodology to measure the impact of price changes on poverty measured by an entire class of additive separable poverty measures. This impact is captured by means of price elasticity of poverty. The total effect of changes in price on poverty is explained in terms of two components. The first component is the income effect of the change in price and the second is the distribution effect captured by the price changes. It is the distribution effect which determines whether the price changes benefit the poor proportionally more (or less) than the non-poor. This paper also derives a new price index for the poor (PIP). While this index can be computed for any poverty measures, our empirical analysis applied to Brazil is based on three poverty measures, the head-count ratio, the poverty gap ratio and the severity of poverty. The empirical results show that price changes in Brazil during the 1999-2006 period have occurred in a way that favors the non-poor proportionally more than the poor. Nevertheless, during the last 2-3 years the price changes have favored the poor relative to the non-poor.
\end{abstract}

Keywords: Inflation, Price elasticity, Money metric utility, Price index for the poor, Pro-Poor, Poverty.

JEL Classification: B41, D11, D12, E31, 132, O54

\footnotetext{
* The authors are grateful to Rafael Osorio for his invaluable assistance and excellent work in matching price data with a household survey for a large number of commodities. We also would like to acknowledge Sergei Soares, Marcelo Neri and Marcelo Medeiros for their helpful comments.

** E-mail address for correspondence: hyun.son@undp-povertycentre.org ; Tel: 55-61-2105 5025;

Fax: 55-61-2105 5001/5002.
} 


\section{INTRODUCTION}

Changes in relative prices can have a large impact on poverty yet most studies do not address the issue of relative prices. ' In the measurement of trends in poverty, a common method is to update the poverty line over time using the Laspeyres price index, which uses the average budget shares as the weights. This index is completely insensitive to the distributional impact of prices.

Kenneth Arrow in 1958 noted that people with lower incomes are likely to have consumption patterns that differ from those with higher incomes. For instance, people with lower incomes spend more of their budget, on average, on necessities than they spend on luxuries. This means that if the prices of necessities increase faster than those of luxuries, the poor will be more adversely affected than the non-poor.

The main objective of this paper is to systematically capture the impact of prices on poverty. Poverty can be measured by several indices; the most common among them are the class of Foster, Greer and Thorbecke (1984) poverty measures. Every poverty measure gives different weights to the poor depending on how far below the poverty line they are. Therefore, the impact of prices on poverty will differ depending on which poverty measure is used. In this paper, we develop a methodology to measure the impact of prices on poverty measured by an entire class of additive separable poverty measures. This impact is captured by means of the price elasticity of poverty, which is decomposed as the sum of two components. The first component is the income effect of price change and second component is the distribution effect. It is the distribution effect, which determines whether price changes are pro-poor or anti-poor.

In this paper, we also derive a new price index for the poor (PIP). The weights used in the new indices are derived from the price elasticity of poverty. Thus, there will be a monotonic relationship between the PIP and the changes in poverty; the higher the index, the greater the increase in poverty. ${ }^{2}$ Price changes are judged as pro-poor (or anti-poor) if the PIP is less (or greater) than the Laspeyres price index.

We introduce our actual analysis as follows: Sections 2-6 are devoted to the methodology to define and derive the new price index for the poor. Following that, the seventh section sets out the analysis of our empirical results, whereby the methodology developed in the paper is applied to Brazil. The final section offers some concluding remarks.

\section{POVERTY MEASURES}

Suppose income $x$ of an individual is a random variable with density function $f(x)$ and if $z$ is the poverty line of this individual, then a class of additive separable poverty measures can be written as

$$
\theta=\int_{0}^{z} P(z, x) f(x) d x
$$


where $P(z, x)$ can be interpreted as the deprivation suffered by an individual with income $x$, which takes the value of zero if $x \geq z$ and positive otherwise. This suggests that an individual suffers deprivation only if his or her income is below the poverty line. The poverty measure $\theta$ is the average deprivation suffered by the whole society.

Foster, Greer and Thorbecke's (1984) class of poverty measures are obtained when we substitute $P(z, x)=\left(\frac{z-x}{z}\right)^{\alpha}$ in (1):

$$
\theta_{\alpha}=\int_{0}^{z}\left(\frac{z-x}{z}\right)^{\alpha} f(x) d x
$$

where $\alpha$ is the parameter of inequality aversion. When $\alpha=0, \theta_{0}=\mathrm{H}$, the head-count measure. This measure gives equal weight to all poor irrespective of the intensity of poverty suffered by them. When $\alpha=1$, each poor individual is weighed by his or her income shortfall from the poverty line. This measure is called the poverty gap ratio. For $\alpha=2$, the weight given to each poor person is proportional to the square of the income shortfall of the poor from the poverty line. This is called the 'severity of poverty measure'. We shall attempt to calculate the impact of price changes on these three poverty measures in Brazil.

\section{PRICE ELASTICITY OF INDIVIDUAL MONEY METRIC UTILITY}

Suppose that $\mathbf{p}$ is a $m \times 1$ price vector in the base year, which changes to the price vector $\mathbf{p}^{*}$ in the terminal period. Following that, we want to know how this change will affect an individual's real income (or expenditure). ${ }^{3}$ To answer this question, we consider the expenditure function $\mathrm{e}(\mathbf{u}, \mathbf{p})$, which is the expenditure required to obtain $u$ level of utility when the price vector is $\mathbf{p} .{ }^{4}$ The real income of the individual with income $x$ will change by ${ }^{5}$

$$
\Delta x=-\left[\mathrm{e}\left(\mathrm{u}, \mathbf{p}^{*}\right)-\mathrm{e}(\mathrm{u}, \mathbf{p})\right]
$$

which on using Taylor expansion gives:

$$
\Delta x=-\sum_{i=1}^{m}\left(p_{i}^{*}-p_{i}\right) q_{i}(x)=\sum_{i=1}^{m} \Delta p_{i} q_{i}(x)
$$

where $q_{i}(x)=\frac{\partial e(u, p)}{\partial p_{i}}$ is the demand for the ith commodity by the individual with income $x$. This equation implies that the change in money metric individual welfare is equal to the change in the cost of the consumption basket due to the change in prices. It is easy to show from (4) that the elasticity of the individual money metric utility with respect to the $i$ th price is given by 


$$
\frac{\partial x}{\partial p_{i}} \frac{p_{i}}{x}=-\frac{p_{i} q_{i}(x)}{x}=-w_{i}(x)
$$

where $w_{i}(x)$ is the budget share of the ith commodity at income level $x$. This equation implies that if the price of the ith commodity increases by 1 percent, the real income (money metric individual utility) $x$ will decline by $w_{i}(x)$ percent. This result will be used in the next section to derive the poverty elasticity with respect to prices.

\section{PRICE ELASTICITY OF POVERTY}

To begin with, we derive the elasticity of the head-count ratio with respect to the ith price. The head-count ratio can be written as

$$
H=\int_{0}^{z} f(x) d x=F(z)
$$

where $F(z)$ is the probability distribution function at the income level equal to the poverty line $z$.

Suppose _ $u$ is the utility level enjoyed by a person with income equal to the poverty line $z$ when the price vector is $\mathbf{p}$. Following that, we can write

$$
z=e\left(\_u, p\right)
$$

which on differentiating with respect to $p_{i}$ gives

$$
\frac{\partial z}{\partial p_{i}} \frac{p_{i}}{z}=-\frac{p_{i} q_{i}(z)}{z}=-w_{i}(z)
$$

where $w_{i}(z)$ is the budget share of the ith commodity at the poverty line. On differentiating (6) with respect to $p_{i}$, we obtain the elasticity of the head-count ratio with respect to $p_{i}$ as

$$
\eta_{H i}=-\frac{\partial H}{\partial p_{i}} \frac{p_{i}}{H}=\frac{z f(z) w_{i}(z)}{H}
$$

The interpretation of this elasticity is that if the price of the ith commodity increases by 1 percent, the head-count ratio $H$ will increase by $\eta_{H i}$ percent. If all prices increase by one percent, then $H$ will increase by $\eta_{H}$ percent, where $\eta_{H}$ is given by

$$
\eta_{H}=\sum_{i=1}^{m} \eta_{H i}=\frac{z f(z)}{H}
$$

$\eta_{H}$ may be called the total head-count elasticity. This measures the impact of the head-count ratio when all prices increase by 1 percent.

Next, we derive the price elasticity of poverty for the entire class of poverty measures defined in (1). Differentiating (1) with respect to $\mathrm{p}_{\mathrm{i}}$ and using (5), we obtain 


$$
\eta_{\theta i}=\frac{\partial \theta}{\partial p_{i}} \frac{p_{i}}{\theta}=-\frac{1}{\theta} \int_{0}^{z} \frac{\partial P}{\partial x} x w_{i}(x) f(x) d x
$$

This elasticity has a similar interpretation as the elasticity of the head-count ratio: if the price of the ith commodity increases by 1 percent, the poverty measured by $\theta$ will increase by $\eta_{\theta i}$ percent. If all prices increase by one percent, then $\theta$ will increase by $\eta_{\theta}$ percent, where $\eta_{\theta}$ is given by

$$
\eta_{\theta}=\sum_{i=1}^{m} \eta_{\theta i}=-\frac{1}{\theta} \int_{0}^{z} \frac{\partial P}{\partial x} x f(x) d x
$$

which is the total poverty elasticity and where $m$ is the total number of commodities.

Substituting $P(z, x)=\left(\frac{z-x}{z}\right)^{\alpha}$ into (11), the poverty elasticity of the FGT class of poverty measures is given by

$$
\eta_{\alpha i}=\frac{\partial \theta_{\alpha}}{\partial p_{i}} \frac{p_{i}}{\theta_{\alpha}}=\frac{\alpha}{\theta_{\alpha}}\left[\int_{0}^{z}\left(\frac{z-x}{z}\right)^{\alpha-1} w_{i}(x) f(x) d x-\int_{0}^{z}\left(\frac{z-x}{z}\right)^{\alpha} w_{i}(x) f(x) d x\right]
$$

for $\alpha \neq 0$. Summing over all commodities, this equation gives the total elasticity of the FGT measures as

$$
\eta_{\alpha}=\sum_{i=1}^{m} \eta_{\alpha i}=\frac{\alpha}{\theta_{\alpha}}\left[\theta_{\alpha-1}-\theta_{\alpha}\right]
$$

\section{MEASURING THE IMPACT OF PRICES ON POVERTY}

Since $x=e(u, \mathbf{p})$, the poverty measure in (1) can be written as

$$
\theta(\mathbf{p})=\int_{0}^{z} P(z, e(u, \mathbf{p})) f(e(u, \mathbf{p})) d e(u, \mathbf{p})
$$

which shows that $\theta(\mathbf{p})$ is a function of price vector $\mathbf{p}$. When the price vector $\mathbf{p}$ changes to $\mathbf{p}^{*}$, the poverty measure $\theta(\mathbf{p})$ will change to $\theta\left(\mathbf{p}^{*}\right)$. Accordingly, the proportional change in poverty $\theta$ due to the change in prices will be given by $\frac{\theta\left(\mathbf{p}^{*}\right)-\theta(\mathbf{p})}{\theta(\mathbf{p})}$, which on applying Taylor expansion can be approximated as 


$$
\frac{\theta\left(\mathbf{p}^{*}\right)-\theta(\mathbf{p})}{\theta(\mathbf{p})}=\sum_{i=1}^{n}\left(\frac{p_{i}^{*}-p_{i}}{p_{i}}\right) \eta_{\theta i}
$$

where $\eta_{\theta i}$ is the elasticity of $\theta$ with respect to the price of the ith commodity as defined in (11). The term on the right hand side of (15) measures the impact of the change in prices on poverty.

How can we measure whether changes in prices are pro-poor or anti-poor? To answer this question, we decompose the elasticity $\eta_{\theta i}$ into the sum of two components:

$$
\eta_{\theta i}=\bar{w}_{i} \eta_{\theta}+\left(\eta_{\theta i}-\bar{w}_{i} \eta_{\theta}\right)
$$

where

$$
\bar{w}_{i}=\frac{\int_{0}^{\infty} x w_{i}(x) f(x) d x}{\int_{0}^{\infty} x f(x) d x}
$$

is the average budget share of the ith commodity. The first term on the right hand side of (16) is the income effect of the ith price change, which is always positive. The second term on the right hand side of (16) is the distribution effect of the ith price change, which can be either negative or positive. It is the distribution effect that tells us whether an increase in the $i$ th price redistributes income in favor of the poor or the non-poor. If the distribution effect is negative (or positive), the increase in the ith price redistributes income in favor of the poor (or nonpoor). This leads us to propose a pro-poor price index $a s^{6}$

$$
\varphi_{i}=\frac{\eta_{\theta i}}{\bar{w}_{i} \eta_{\theta}}
$$

If $\varphi_{i}$ is less than 1 , an increase in the ith price hurts the poor proportionally less than the non-poor, that is, the price increase in the ith commodity is pro-poor. Similarly, if $\varphi_{i}$ is greater than 1 , then the ith price increase is anti-poor. Thus, $\varphi_{i}$ can be used to analyze how changes in the prices of different commodities would affect poverty.

To measure the impact of prices on poverty, we substitute (16) into (15). This leads to the total effect of the changes in prices on poverty, which is the sum of two components:

$$
\sum_{i=1}^{n}\left(\frac{p_{i}^{*}-p_{i}}{p_{i}}\right) \eta_{\theta i}=\sum_{i=1}^{n}\left(\frac{p_{i}^{*}-p_{i}}{p_{i}}\right) \bar{w}_{i} \eta_{\theta}+\sum_{i=1}^{n}\left(\frac{p_{i}^{*}-p_{i}}{p_{i}}\right)\left(\eta_{\theta i}-\bar{w}_{i} \eta_{\theta}\right)
$$

The first term on the right hand side of (18) measures the impact of prices on poverty under a counter-factual situation when all prices had increased at the same rate. The second term on the right hand side of (18) measures the impact of changes in relative prices on poverty. The relative changes in prices are pro-poor (or anti-poor) if the second term on the right hand side of (18) is negative (or positive). 


\section{PRICE INDEX FOR THE POOR (PIP)}

We now move on to define a price index for the poor (PIP). Equation (15) estimates the proportional change in the poverty measure $\theta$ when the price vector $\mathrm{p}$ changes to $\mathrm{p}^{*}$. Suppose we have a counter-factual situation whereby all prices change by $100 \times(1-\lambda)$ percent, i.e. $p_{i}^{*}=\lambda p_{i}$. Then $\lambda$ may be called the price index for the poor if it gives the same change in a poverty measure $\theta$ as the given change in the price vector from $\mathrm{p}$ to $\mathrm{p}^{*}$. Utilizing (15), we derive $\lambda$ as:

$$
\lambda=\sum_{i=1}^{m} \frac{p_{i}^{*}}{p_{i}}\left(\frac{\eta_{\theta i}}{\eta_{\theta}}\right)
$$

which is the PIP for the poverty measure $\theta$. Weights implied by this index are the poverty weights implicit in poverty measures. Different poverty measures imply different PIPs. In this paper, we compute PIP separately for three poverty measures, including the head-count ratio, the poverty gap ratio and the severity of poverty ratio.

The widely used Laspeyres price index can be written as

$$
L=\sum_{i=1}^{m} \frac{p_{i}^{*}}{p_{i}} \bar{w}_{i}
$$

where $\bar{w}_{i}$ is the average budget share of the ith commodity. Using equations (17), (19) and (20), we can write

$$
\lambda=L+\sum_{i=1}^{m} \frac{p_{i}^{*}}{p_{i}} \bar{w}_{i}\left(\varphi_{i}-1\right)
$$

which provides our main result that a relative price change is pro-poor (or anti-poor) if $\lambda$ is less (or greater) than $L$.

\section{EMPIRICAL ILLUSTRATION FROM BRAZIL}

Our empirical illustration is based on the 2002-03 Brazilian Family Expenditure Survey (POF) covering 48,470 households throughout the entire country. The survey provides detailed incomes and consumption expenditures for each household. We have utilized unit record data to calculate the poverty weights.

We obtained monthly price data from the Institute of Geography and Statistics (IBGE). These data were collected for twelve metropolitan regions throughout the country over the period from August 1999 to July 2006. The twelve regions include: 


\begin{tabular}{|l|l|}
\hline 1. Belem, Para & 7. Sao Paulo \\
\hline 2. Fortaleza, Ceara & 8. Curitiba, Parana \\
\hline 3. Recife, Pernambuco & \begin{tabular}{l} 
9. Rio Grande do Sul \\
\hline 4. Salvador, Bahia
\end{tabular} \\
\hline 5. Belo Horizonte & 11. Goiania, Goias \\
\hline 6. Rio de Janeiro & 12. Non-metropolitan region \\
\hline
\end{tabular}

The price data supplied to us by the IBGE provided detailed prices for 472 items of household consumption, including 219 food items and 253 non-food items covering almost all items of food and non-food consumed by the population. We aggregated all the food and non-food items of consumption into 51 commodity groups which we could exactly match in the price data and the POF. The national prices for the 51 commodity groups were calculated as the weighted average of the prices for the same 51 commodity groups available from the twelve regions, with weights proportional to the population of each region.

To begin with, we calculated the price elasticity of poverty for the three poverty measures, the head-count ratio, the poverty gap ratio and the severity of poverty. These estimates were obtained for 51 commodity groups although in Table 1, we present the aggregated estimates for only 7 broad categories of consumption. The table also presents the estimates of pro-poor price index. The price elasticity of food for the head-count ratio is 0.42 , suggesting that if food prices increase by 1 percent, the head-count ratio will increase by 0.42 percent. Similarly, if non-food prices increase by 1 percent, the head-count poverty measure will increase by 1.02 percent. If all prices increase by 1 percent, the rise in the head-count ratio will be 1.44 percent.

The results also reveal that the price elasticity increases with a higher-order poverty index such as the severity of poverty. This implies that the ultra-poor are more adversely affected by price increases compared to the poor.

TABLE 1

Price elasticity of poverty

\begin{tabular}{lccccccc}
\hline \multirow{2}{*}{ Items of consumption } & \multicolumn{2}{c}{ Head-count ratio } & & \multicolumn{2}{c}{ Poverty gap ratio } & \multicolumn{2}{c}{ Severity of poverty } \\
\cline { 2 - 3 } \cline { 6 - 7 } & Elasticity & $\begin{array}{c}\text { Pro-Poor } \\
\text { Price index }\end{array}$ & Elasticity & $\begin{array}{c}\text { Pro-Poor } \\
\text { Price index }\end{array}$ & Elasticity & $\begin{array}{c}\text { Pro-Poor } \\
\text { Price index }\end{array}$ \\
\hline Food & 0.42 & 1.62 & 0.56 & 1.77 & 0.65 & 1.81 \\
Non-food & 1.02 & 0.86 & 1.21 & 0.83 & 1.36 & 0.82 \\
Housing & 0.63 & 1.11 & 0.77 & 1.11 & 0.89 & 1.12 \\
Clothing & 0.11 & 1.24 & 0.14 & 1.28 & 0.16 & 1.26 \\
Transport & 0.11 & 0.46 & 0.11 & 0.36 & 0.11 & 0.32 \\
Health & 0.09 & 0.68 & 0.10 & 0.61 & 0.10 & 0.56 \\
Entertainment & 0.05 & 0.76 & 0.06 & 0.70 & 0.06 & 0.69 \\
Education \& communication & 0.03 & 0.33 & 0.03 & 0.30 & 0.04 & 0.30 \\
\hline Total & 1.44 & 1.00 & 1.77 & 1.00 & 2.01 & 1.00 \\
\hline
\end{tabular}

Source: Authors' calculation.

The pro-poor price index helps us to understand how changes in prices of each consumption item would affect the distribution of income. The pro-poor price indices for food, 
clothing and housing are greater than unity for all the three poverty measures. This implies that an increase in the prices of these items will adversely affect the poor more than the nonpoor. The index for the other remaining four non-food items - including transport, health, entertainment and education and communication - is less than 1. This result suggests that the price increases of these items will reduce the relative inequality in income. This information could be useful in formulating indirect tax policies. Furthermore, in many countries, the government provides services for which charges are made to private users. In the formulation of such price policies, it is important to know how changes in prices have an impact on poverty. The pro-poor price index can be used in formulating the government's price policies.

The pro-poor price index facilitates an ex ante analysis of price effects on poverty. It is also of interest to find out the extent to which ex post changes in prices have impacted poverty. Table 2 presents the ex post percentage changes in poverty due to the changes in prices. These estimates capture the pure price effects when other factors remain constant. As a result of the price increase, the head-count ratio has increased by 91.93 percent during the period 1999 2006. The percentage increases in the poverty gap ratio as well as in the severity of poverty have been even much greater, 113.48 and 129.41 percent, respectively.

TABLE 2

Percentage change in poverty due to changes in prices explained by income and distribution effects

\begin{tabular}{|c|c|c|c|}
\hline Period & Total change & Income effect & Distribution effect \\
\hline & \multicolumn{3}{|c|}{$\%$ change in the head-count ratio } \\
\hline $99-00$ to $00-01$ & 9.75 & 9.87 & -0.12 \\
\hline $00-01$ to $01-02$ & 14.81 & 11.74 & 3.07 \\
\hline $01-02$ to $02-03$ & 23.54 & 19.15 & 4.38 \\
\hline $02-03$ to $03-04$ & 13.56 & 12.22 & 1.35 \\
\hline 03-04 to $04-05$ & 7.57 & 9.80 & -2.23 \\
\hline $04-05$ to $05-06$ & 4.77 & 6.88 & -2.11 \\
\hline \multirow[t]{2}{*}{$99-00$ to $05-06$} & 91.93 & 86.20 & 5.73 \\
\hline & \multicolumn{3}{|c|}{$\%$ change in the poverty gap ratio } \\
\hline $99-00$ to $00-01$ & 12.11 & 12.16 & -0.05 \\
\hline $00-01$ to $01-02$ & 18.97 & 14.45 & 4.52 \\
\hline $01-02$ to $02-03$ & 30.20 & 23.58 & 6.62 \\
\hline $02-03$ to $03-04$ & 16.63 & 15.04 & 1.59 \\
\hline 03-04 to 04-05 & 8.59 & 12.07 & -3.47 \\
\hline $04-05$ to $05-06$ & 5.18 & 8.47 & -3.29 \\
\hline \multirow[t]{2}{*}{$99-00$ to $05-06$} & 113.48 & 106.13 & 7.35 \\
\hline & \multicolumn{3}{|c|}{$\%$ change in the severity of poverty } \\
\hline $99-00$ to $00-01$ & 13.82 & 13.78 & 0.04 \\
\hline $00-01$ to $01-02$ & 22.09 & 16.38 & 5.71 \\
\hline $01-02$ to $02-03$ & 34.89 & 26.73 & 8.16 \\
\hline $02-03$ to $03-04$ & 18.90 & 17.05 & 1.86 \\
\hline 03-04 to $04-05$ & 9.37 & 13.67 & -4.31 \\
\hline $04-05$ to $05-06$ & 5.57 & 9.60 & -4.03 \\
\hline $99-00$ to $05-06$ & 129.41 & 120.28 & 9.13 \\
\hline
\end{tabular}

Source: Authors' calculation. 
The percentage change in poverty due to price changes can be decomposed into two components, income and distribution effects. The income effect measures the change in poverty when all prices increase uniformly, whereas the distribution effect captures the change in poverty because of changes in relative prices. The distribution effect reveals how changes in relative prices have affected the poor relative to the non-poor. It can be seen that the distribution effect implied by the head-count ratio is 5.73 in the $1999-2006$ period. This suggests that changes in relative prices have contributed to a rise in the head-count ratio by 5.73 percent between 1999 and 2006. In comparison, the magnitudes of the poverty gap ratio and the severity of poverty are far greater, 7.35 and 9.13, respectively. Taking everything into account, it can be said that the changes in relative prices have not been pro-poor in Brazil during the period 1999 - 2006.

Looking at each period separately, we find a negative distribution effect for 2003/04 $2004 / 05$ and 2004/05 - 2005/06. Hence, for the past two to three years the changes in prices have become pro-poor. According to recent study by Kakwani, Neri and Son (2006), income inequality in Brazil has been declining for the past two years. This study suggests that the inequality of real income in Brazil has fallen even more than that of nominal income.

TABLE 3

Weights implied by poverty indices

\begin{tabular}{|c|c|c|c|c|}
\hline \multirow{2}{*}{ Items of consumption } & \multirow{2}{*}{$\begin{array}{l}\text { Laspeyres } \\
\text { Index }\end{array}$} & \multicolumn{3}{|c|}{ Price Index for the Poor (PIP) } \\
\hline & & Head-count ratio & Poverty gap ratio & Severity of poverty \\
\hline Food & 17.95 & 29.06 & 31.70 & 32.43 \\
\hline Non-food & 82.05 & 70.94 & 68.30 & 67.57 \\
\hline Housing & 39.32 & 43.74 & 43.64 & 44.09 \\
\hline Clothing & 6.39 & 7.91 & 8.16 & 8.09 \\
\hline Transport & 16.97 & 7.84 & 6.18 & 5.43 \\
\hline Health & 8.91 & 6.10 & 5.40 & 5.03 \\
\hline Entertainment & 4.49 & 3.40 & 3.14 & 3.11 \\
\hline Education \& communication & 5.98 & 1.95 & 1.78 & 1.81 \\
\hline Total & 100.00 & 100.00 & 100.00 & 100.00 \\
\hline
\end{tabular}

The most widely used Laspeyres price index is constructed using the average budget shares of commodities as weights. These weights do not capture the consumption patterns of the poor. In this paper, we have derived the price index for the poor (PIP) based on any given poverty measure. The weights for the PIP are determined from the price elasticity of poverty measures. Thus, every poverty measure will have a different PIP. In this paper, we have computed PIPs for three poverty measures, the head-count ratio, the poverty gap ratio and the severity of poverty. Table 3 presents the weights implicit in these poverty measures for the seven broad expenditure groups.

It can be seen that the weight implied by the Laspeyres price index differs vastly from the one implied by the three price indices for the poor. It is interesting to note, however, that the PIPs for the three poverty measures have very similar weights for the seven commodity groups. This implies that our findings are quite robust irrespective of poverty measures. 
TABLE 4

Inflation rates based on Laspeyres and PIP indices

\begin{tabular}{|c|c|c|c|c|}
\hline \multirow{2}{*}{ Period } & \multirow{2}{*}{$\begin{array}{l}\text { Laspeyres } \\
\text { Index }\end{array}$} & \multicolumn{3}{|c|}{ Price Index for the Poor (PIP) } \\
\hline & & Head-count ratio & Poverty gap ratio & Severity of poverty \\
\hline $99-00$ to $00-01$ & 6.86 & 6.77 & 6.83 & 6.88 \\
\hline 00-01 to 01-02 & 8.15 & 10.28 & 10.70 & 10.99 \\
\hline $01-02$ to $02-03$ & 13.30 & 16.34 & 17.04 & 17.36 \\
\hline $02-03$ to $03-04$ & 8.48 & 9.42 & 9.38 & 9.41 \\
\hline $03-04$ to $04-05$ & 6.81 & 5.26 & 4.85 & 4.66 \\
\hline $04-05$ to $05-06$ & 4.78 & 3.31 & 2.92 & 2.77 \\
\hline $99-00$ to $05-06$ & 59.86 & 63.84 & 64.01 & 64.40 \\
\hline
\end{tabular}

Source: authors' calculation.

Table 4 presents the inflation rates computed based on the Laspeyres and PIP indices. Note that the PIP inflation rates are higher than the Laspeyres inflation rate for the period $1999 / 00$ - 2003/04. However, in the following two periods (2003/04 - 2004/05 and 2004/05 2005/06) the Laspeyres inflation rates are higher than the PIP inflation rates. This is also clearly depicted in Figure 1. Overall, the changes in relative prices have adversely impacted on the poor during the entire period, but relative prices have changed in favor of the poor in the last two sub-periods.

FIGURE 1

Inflation rates based on Laspeyres and PIP indices

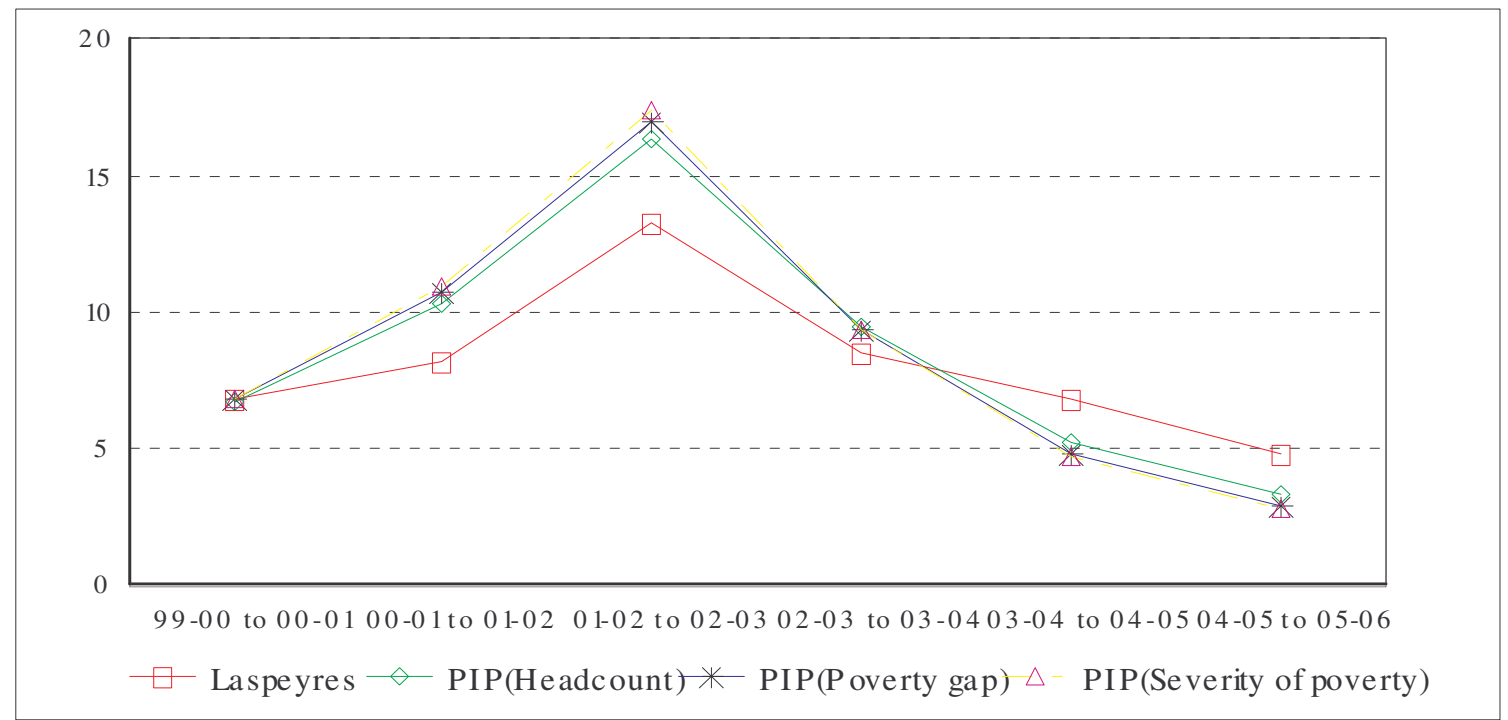

We also computed Laspeyres and PIP indices separately for food and non-food items of consumption. The results depicted in Figures 2 and 3 show that Laspeyres and PIP indices give very similar inflation rates for food but the differences are quite wide for non-food items. This result can be explained in terms of differences in consumption patterns of the poor and the non-poor within the food and non-food groups of items. The consumption patterns of the 
poor and the non-poor are similar in food items, so we did not observe wide differences in food inflation rates between the Laspeyres and PIP indices. However, in non-food items there were large differences in the consumption patterns of the poor and the non-poor, which resulted in wide differences in price indices.

FIGURE 2

Food inflation rates based on Laspeyres and PIP indices

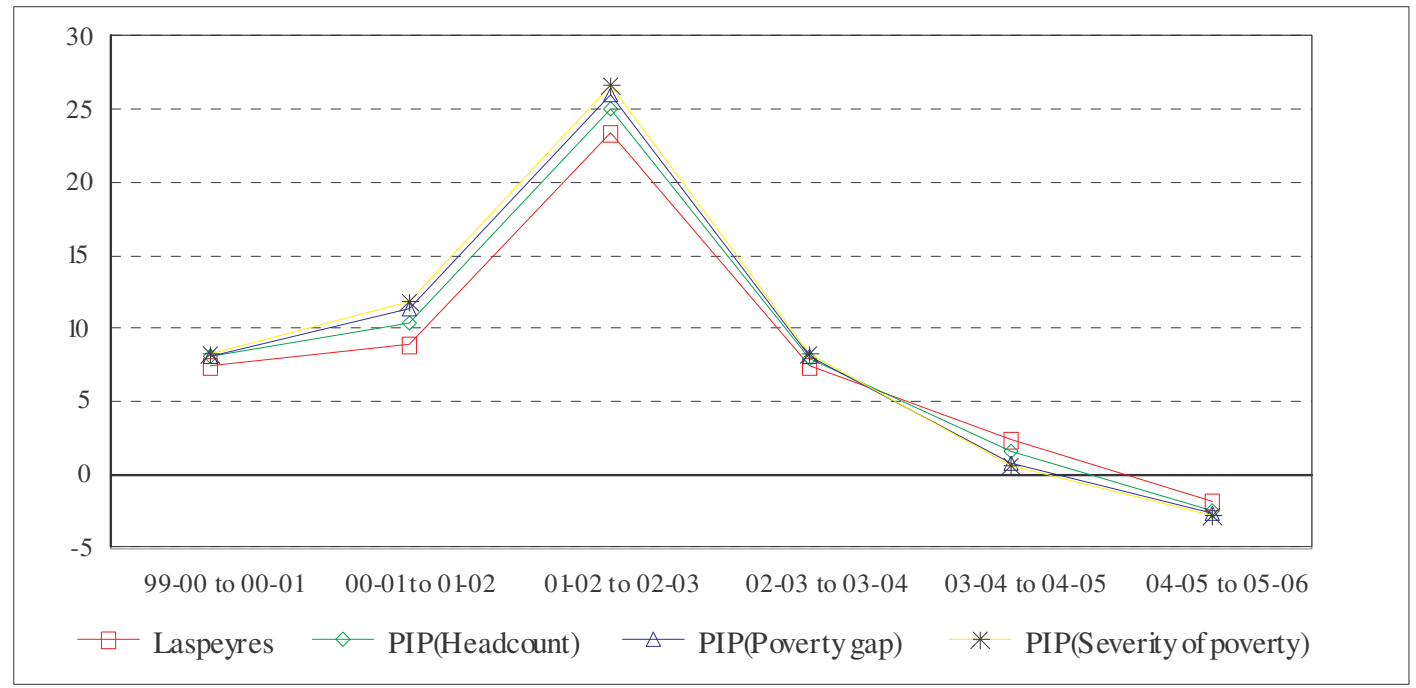

FIGURE 3

Non-food inflation rates based on Laspeyres and PIP indices

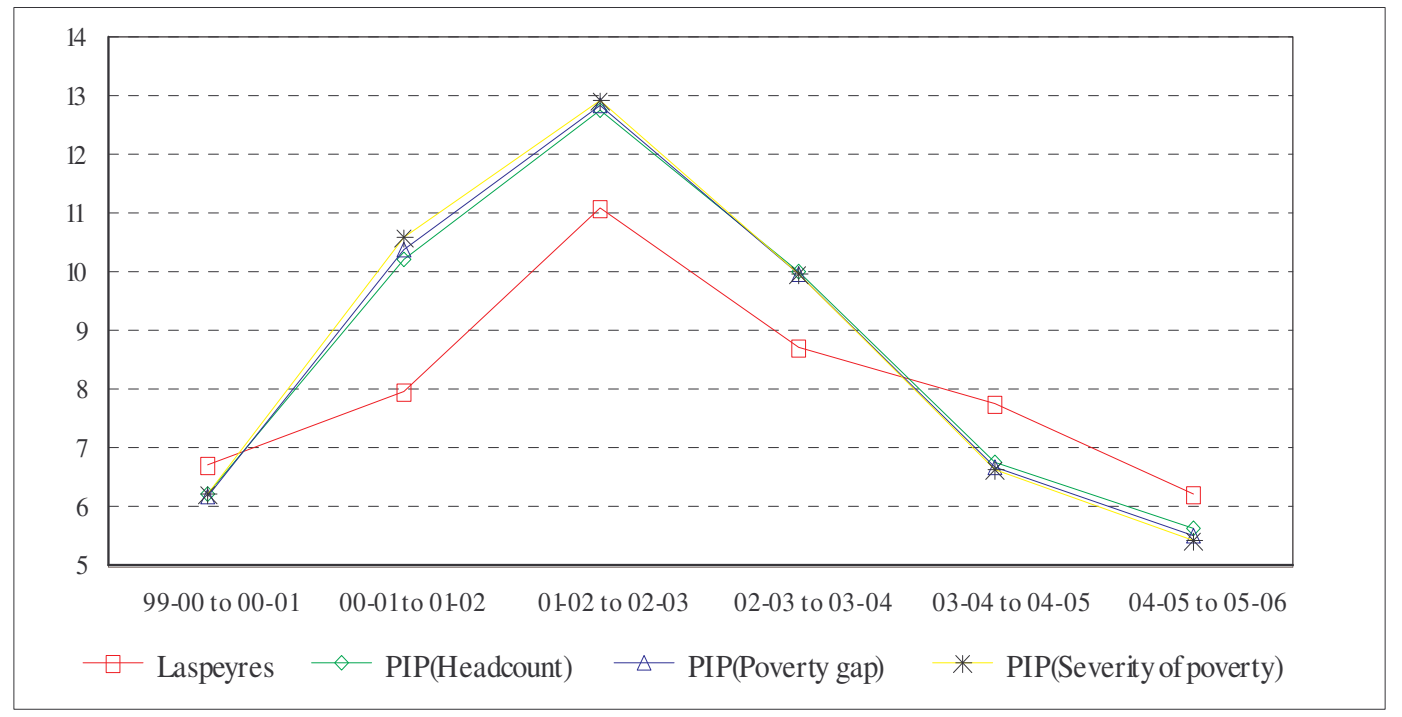

\section{CONCLUDING REMARKS}

Prices play an important role in our lives. People differ in terms of their needs and consumption patterns, so the effect of the price changes will also be different from one individual to another. If the prices of necessities increase faster than those of luxuries, the poor 
will be hurt more than the non-poor. If our concern is with protecting the poor, it is important to know how changes in prices affect the poor. The main objective of this paper was to measure the impact of price changes on poverty. Our methodological approach to achieve that aim was based on consumer demand theory.

Most government policies have a direct and indirect impact on the prices of different commodities. For instance, in many countries, the government provides services in the areas of health, education, utilities and transportation, for which charges are made to private users. In the formulation of such price policies, it is important to know how changes in the prices of these services have an impact on the poor. In this paper, we have developed a pro-poor price index, which helps us to understand how changes in the price of each consumption item would affect the distribution of income. This index can be useful in the formulation of governments' price policies to have the least adverse impact on the poor.

The percentage change in poverty due to price changes can be decomposed into two components, income and distribution effects. The income effect measures the change in poverty when all prices increase uniformly, whereas the distribution effect captures the change in poverty because of changes in relative prices. The distribution effect reveals how the changes in relative prices have affected the poor relative to the non-poor. The empirical evidence presented in this paper shows that the changes in relative prices have not been propoor in Brazil during the period 1999 - 2006. This trend has changed during the last two to three years, when the changes in relative prices have become pro-poor.

In the measurement of trends in poverty, a common method is to update the poverty line over time using the Laspeyres price index, which uses the average budget shares as the weights. This index is not relevant to determining the price changes of goods and services bought by the poor. In this study, we have developed a price index for the poor (PIP), which captures systematically the consumption patterns of the poor by means of price elasticity of poverty. The empirical illustration for Brazil showed that the poor have generally faced higher inflation rates than the general population, although this trend has changed during the past 2-3 years. As such, the level of government assistance rendered to the poor, as well as poverty rates, would be expected to be different if it used a price index specifically designed to reflect the spending patterns of the poor. 


\section{REFERENCES}

Agenor, P. R. (1998) "Stabilization Policies, Poverty and the Labor Market", mimeo, IMF and World Bank.

Amble, N. and Stewart, K. (1994), "Experimental price index for elderly consumers", Monthly Labor Review, May, 11-16.

Arrow, K. J. (1958) "The Measurement of Price Changes", in The Relationship of Prices to Economic Stability and Growth, Joint Economic Committee, U.S. Congress, March 31, 1958.

Blank, R. M. and Blinder, A. S. (1986) "Macroeconomics, Income distribution, and Poverty", in Shelton Danzinger and Daniel Weinberg, eds., Fighting Poverty, Cambridge, MA, Harvard University Press.

Boskin, M. and Hurd, M. (1985) "Indexing Social Security Benefits: A separate price index for the elderly", Public Finance Quarterly, October, 436-49.

Cardose, E. (1992) "Inflation and Poverty", National Bureau of Economic Research Working Paper No. 4006.

Ferreira, F., Lanjouw, P. and Neri, M. (2003) "A Robust Poverty Profile for Brazil using Multiple Data Sources", Revista Brasileira de Economia 57 (1), 59-92: Brazil.

Son, H. H. and Kakwani, N. (2006) "Measuring Impact of Prices on Inequality: with applications to Thailand and Korea", Journal of Economic Inequality, 2006 (Aug.), Vol. 4, No. 2, 181-207.

Son, H. H. (2006) "Assessing the Pro-Poorness of Government Fiscal Policy: The Thailand Case", 2006 (July), Public Finance Review, Vol. 34, No. 4, 1-23. 


\section{NOTES}

1. Many studies have focused on price indices for specific demographic groups including the poor. Related studies have examined the impact of inflation on low-income consumers, and a few have applied different price indices to adjust poverty thresholds and analyzed the impact of those adjustments on poverty rates. (see Michael and Hagemann (1982), Kokoski (1987), Amble and Stewart (1994), Boskin and Hurd 1985, Jorgenson and Slesnick 1983). Yet, none of these studies provide a theoretical framework to capture the impact of prices on poverty.

2. Note that this relationship will be the first-order approximation because in this study we ignore the substitution effect of price changes.

3. In this paper, expenditure and income are interchangeably used as a welfare measure.

4. This function is also referred to as the cost function in the literature. See Deaton and Muellbauer (1980).

5. This equation is based on Hick's (1946) compensation variation CV $=\left[e\left(u, \mathbf{p}^{*}\right)-e(u, \mathbf{p})\right]$, which is the compensation that should be given to an individual to maintain his or her utility level the same as before the price change.

6. Son (2006) has used this index to analyze the pro-poorness of government fiscal policy in Thailand. 
International Poverty Centre SBS - Ed. BNDES, $10^{\circ}$ andar 70076900 Brasilia DF Brazil

povertycentre@undp-povertycentre.org www.undp.org/povertycentre

Telephone +55 6121055000

Fax +55 6121055001 